\title{
Ambient measurements of monoterpenes near Cannabis cultivation facilities in Denver, Colorado
}

\author{
Chi-Tsan Wang ${ }^{\mathrm{a}}$, Kirsti Ashworth ${ }^{\mathrm{b}, 1}{ }$, Christine Wiedinmyer ${ }^{\mathrm{c}}$, John Ortega ${ }^{\mathrm{d}}$, Peter C. Harley ${ }^{\mathrm{d}}$, \\ Quazi Z. Rasool ${ }^{\mathrm{e}}$, William Vizuete ${ }^{\mathrm{a}, "}$ \\ ${ }^{a}$ Department of Environmental Sciences \& Engineering, University of North Carolina, Chapel Hill, NC, USA \\ ${ }^{\mathrm{b}}$ Lancaster Environment Centre, Lancaster University, UK \\ ${ }^{\mathrm{c}}$ Cooperative Institute for Research in Environmental Sciences, University of Colorado Boulder, Boulder, CO, USA \\ ${ }^{\mathrm{d}}$ Denver, Colorado, USA \\ e Pacific Northwest National Laboratory, Richland, WA, USA
}

\section{H I G H L I G H T S}

- Measurements near cannabis facilities increased background concentrations of monoterpenes by four times.

- The types of monoterpenes that were measured varied widely across Denver, suggesting a diverse set of emission profiles.

- Composition of measurements near emission sources were dominated by d-limonene, bmyrcene, and a-pinene.

A R T I C L E I N F O

Keywords:

Cannabis spp.

Monoterpene

Ambient measurement

Cannabis Cultivation

\begin{abstract}
A B S T R A C T
Colorado was one of the first US states to legalize the industrial-scale cultivation of Cannabis spp. for recreational purposes. In March 2018, there were 609 indoor Cannabis cultivation facilities (CCFs) in operation in Denver County with a recorded 550,000 mature plants (higher than 8 inches) under cultivation at any given time. It is known that cultivation of Cannabis spp. produces emissions of a group of highly reactive hydrocarbons, monoterpenes. There have been limited studies that have quantified mixing ratios of emitted monoterpenes in air outside CCFs. A field campaign was conducted in August 2016 in Denver County focused on six different CCF clusters near the intersection of interstate highways I-25 and I-70 during which a total of 150 ambient air samples were collected. Monoterpene mixing ratios near CCFs were $\sim 408 \pm 203$ pptv; 4-8 times higher than samples collected from a "background" site located at the Denver City Park (75 \pm 25 pptv). The composition of samples taken near CCFs were dominated by d-limonene (30\%), $\beta$-myrcene (20\%), and $\alpha$-pinene (15\%), which is similar to previously reported emission factors for Cannabis spp. Since $\beta$-myrcene was only detected in leaf enclosure studies, indoor CCF observations and ambient samples near CCFs and not detected at a background site, this particular compound could be used as a tracer for the Denver Cannabis production industry. The monoterpene speciation in ambient measurements varied across Denver suggesting differences in emissions between different Cannabis spp., or different growth stages. Given the observed variabilities in both composition and emission rates, it is critical for the accuracy of emissions inventories to develop strain-specific emission factors. This information, coupled with detailed information on each CCF, would greatly reduce the uncertainties currently present in monoterpene emission estimates for the Cannabis industry and their potential impact on air quality.
\end{abstract}

\section{Introduction}

On January 1st' 2014, the cultivation, processing, and sale of Cannabis for recreational use became legal in the state of Colorado.
There were 360 facilities growing Cannabis for medical purposes in Denver County at the end of 2013. By 2018 the industry expanded to 608 medical and recreational Cannabis Cultivation Facilities (CCFs) in Denver County (CDOR, 2018). These CCFs are all registered and licensed via

\footnotetext{
* Corresponding author.

E-mail address: vizuete@unc.edu (W. Vizuete).

1 Co-first author.
} 
the Colorado Department of Revenue (DOR), with a recorded total of $>550,000$ mature ( $>8$ inches) Cannabis plants under cultivation in Denver County at any given time (Hartman et al., 2018). These new CCFs tend to be clustered around major highways, which offer ease of access for incoming raw materials and to the markets for end products. Where CCFs abut residential neighbourhoods, complaints to Colorado Department of Public Health and Environment (CDPHE) regarding odour nuisance have soared (Murray, 2016; Rusch, 2016) as the volatile compounds responsible for the characteristic smell of Cannabis are released and dispersed from CCF ventilation systems.

There has historically been considerable interest in the volatile organic compounds (VOCs) found in Cannabis spp. and its products, and many previous studies have measured these compounds in dried plant material and essential oils (Hood et al., 1973; Turner et al., 1980; Ross and ElSohly, 1996; Rice and Koziel, 2015). Over 100 different compounds have been identified in the headspace above these materials; the most common of which are monoterpenes $\left(\mathrm{C}_{10} \mathrm{H}_{16}\right)$ that include: $\alpha$-pinene, $\beta$-pinene, $\beta$-myrcene, $d$-limonene, and cis-ocimene; sesquiterpenes $\left(\mathrm{C}_{15} \mathrm{H}_{24}\right)$ including $\beta$-caryophyllene, $\alpha$-farnesene, and $\beta$-humulene; and the terpene alcohols $\left(\mathrm{C}_{10} \mathrm{H}_{18} \mathrm{O}\right)$ such as linalool, borneol, and terpineol (Hood et al., 1973; Turner et al., 1980; Ross and ElSohly, 1996; McPartland and Russo, 2001; Rice and Koziel, 2015). It has also been reported that more odiferous compounds (such as nonanal, decanol, cymene, and benzaldehyde) need only be present in low mixing ratios to be discernible to humans and animals (Rice and Koziel, 2015).

Only a handful of studies, however, have investigated emissions from growing Cannabis spp. plants. Three of these measured mixing ratios of volatiles inside growing and processing rooms in cultivation facilities. The first study took place in small (illicit) operations with $\sim 100$ plants per room and found mixing ratios of monoterpenes as high as $100 \mathrm{ppbv}$ (Martyny et al., 2013), i.e. over an order of magnitude higher than levels observed in high-emitting natural ecosystems such as forests (Ortega et al., 2014; Yanez-Serrano et al., 2015, 2018; Acton et al., 2016; Emmerson et al., 2016). The second study reported average monoterpene levels in CCF budding and flowering rooms to be $\sim 360 \mathrm{ppbv}$ (Southwellb et al., 2017). Most recently, researchers measured monoterpene mixing ratios between $20 \mathrm{ppbv}$ and $1000 \mathrm{ppbv}$ inside four CCFs in California and Nevada (Samburova et al., 2019).

Wang et al. (2019b) measured emissions of volatiles directly from individual live plants of four different Cannabis spp. strains enclosed in chambers. The authors found that although the compounds d-limonene, and $\beta$-myrcene were the most commonly emitted compounds from each strain, the relative emission rates varied between strains. Total monoterpene emission rates from plants in the vegetative stage also varied by strain and had a range of 4.9-8.7 $\mu \mathrm{gC} \mathrm{dwg}{ }^{-1} \mathrm{~h}^{-1}$ (where dwg is dry weight in $\mathrm{g}$ ). This is higher than most pine trees in Colorado (Guenther et al., 1995, 2006; Ortega and Helmig, 2008; Ortega et al., 2008).

In subsequent work, Wang et al. (2019) developed a monoterpene emissions inventory of CCFs across Colorado and estimated that total emissions could be as high as 362 tons year $^{-1}$ for Denver County alone. There is considerable uncertainty in this estimate as assumptions were needed regarding the number of plants per facility $(0-50,000)$, dry weight per plant $(1-2500 \mathrm{~g})$ and emission capacity $\left(10-100 \mu \mathrm{g} \mathrm{dwg}{ }^{-1}\right.$ $\mathrm{h}^{-1}$ ). Prior to the introduction of this industry, it was estimated that Denver County had total emissions of biogenic VOCs (BVOCs) of $\sim 265$ tons year ${ }^{-1}$ (IWDW, 2017). Thus, the addition of the Cannabis industry could increase BVOC emissions by up to $362(+136 \%)$ tons year $^{-1}$ in Denver County (Wang et al., 2019). Monoterpenes are highly reactive; their atmospheric lifetimes range from seconds to hours and the products of their oxidation reactions include secondary air pollutants such as ground-level ozone and particulate matter (PM) (Seinfeld and Pandis, 2006). When Wang et al. (2019) included monoterpene emissions from CCFs in an air quality model in the configuration used by the State of Colorado and EPA, they demonstrated these emissions were sufficient to increase hourly average ozone levels by as much as 1 ppbv per 1000 tons per year of monoterpenes released from CCFs.
Given the considerable uncertainties in CCF emissions estimates and the importance of understanding their impacts on local air quality, we carried out a series of ambient sampling studies in the vicinity of CCFs in Denver County, home to $42 \%$ of CCFs and $50 \%$ of Cannabis plants in the state of Colorado (CDOR, 2018). These experiments were designed to determine the composition of monoterpenes released into the atmosphere from active CCFs to constrain model predictions (Wang et al., 2019) and reduce uncertainties associated with emission factors (Wang et al., 2019b). This study focused on Park Hill, River North Art District, Sunnyside, Lincoln Park and Northeast areas across Denver County each of which contain high numbers of CCFs.

\section{Methods}

\subsection{Sampling}

Ambient air samples were collected onto sorbent cartridges from various locations in the Denver urban area during August 2016 (see Table 1 and Fig. 1). The stainless-steel cartridges (from Markes International, Llantrisant, UK) were loaded with $\sim 400 \mathrm{mg}$ of Tenax TA and Carbograph 5TD in series, to optimise the capture of terpenoids. Air was drawn into the cartridges using small battery-powered pumps, which were placed on a portable platform $\sim 1 \mathrm{~m}$ above the ground. To reduce the effect of losses due to ozone on the adsorbent surfaces, filters impregnated with potassium iodide were used immediately upstream of the sorbent tubes (Pollmann et al., 2005). Two samples were simultaneously collected at each sampling point at approximately hourly intervals, using one low- and one high-flowrate of $\sim 140$ and $\sim 300 \mathrm{~cm}^{3}$ $\min ^{-1}$ respectively. Pump flow rates (used to calculate sample volume) were checked periodically during the campaign period and found to remain stable within $1 \mathrm{ml} \mathrm{min}{ }^{-1}$. Before sampling, clean cartridge tubes were kept capped at both ends and stored in sealed containers. Once used, they were re-capped, transferred to a second sealed container, and kept refrigerated until analysis (at $\sim 1-2{ }^{\circ} \mathrm{C}$ ). The total time from collection to analysis was no longer than one week for any sample. This methodology is consistent with the EPA's TO-17 sampling protocol for toxic organic compounds in ambient air by cartridges (USEPA, 1999).

\subsection{Sampling locations}

Sampling points were selected based on locations of registered CCFs (CDOR, 2018), with latitudes and longitudes confirmed in the field using handheld GPS. Fig. 1 shows the clusters of CCFs targeted in this study, the 6 sampling locations and the background (BG) site. Details pertaining to sampling dates, times, and locations can be found in Tables 1 and S1.

All experiments were conducted in Denver County near the I-70 highway and to the northwest, west, and northeast of central Denver as shown in Fig. 1. Selection of the CCF sampling sites were determined by ease of access to sufficient radial locations at which to collect samples. In experiments $1-3$, paired samples were collected radiating in upwind and downwind directions from a central CCF. Depending on the street layout, sampling points were either aligned in a north-south or southwest-northeast direction to align as closely as possible with the prevailing wind. Sampling points were spaced $\sim 150-200 \mathrm{~m}$ apart, and each was visited only once. Experiments 4, 5, and BG (background) consisted of the collection of paired samples at a single point, at hourly intervals over an 8-h period (roughly 08:00-16:00 Local Time, LT). Experiment BG was conducted at the Denver City Park $\left(104.943^{\circ} \mathrm{W}\right.$, $39.751^{\circ} \mathrm{N}$ ) where the nearest CCF was $2 \mathrm{~km}$ away (see Fig. 1). With this BG experiment vegetation in Denver City Park is dominated by tree species ( $>3000$ individual trees) of which the most common are: maple ( $>200$ counts), ash ( $>150$ counts) and locust ( $>100$ counts) (City and County of Denver, 2019). There are no known cannabis plants in the vicinity, and this location was chosen to enable comparisons between monoterpene emissions from the CCF industry and other biogenic 
Table 1

The summary of sampling dates, duration, number of sampling points and distance to the closest meteorological site.

\begin{tabular}{|c|c|c|c|c|c|c|}
\hline Experiment & Date & $\begin{array}{l}\text { Sample duration } \\
\text { (minutes) }\end{array}$ & $\begin{array}{l}\text { Sample } \\
\text { count }\end{array}$ & $\begin{array}{l}\text { Numbers of sampling locations } \\
\text { (sites) }\end{array}$ & $\begin{array}{l}\text { Distance to Meteorological } \\
\text { site }\end{array}$ & $\begin{array}{l}\text { Meteorological Site } \\
\text { Identification }\end{array}$ \\
\hline 1 & $\begin{array}{l}\text { Aug 2, } 2016 \\
6: 10-12: 10 \\
\text { LT }\end{array}$ & 55 & 20 & 10 & $1.7 \mathrm{~km}$ & $\mathrm{CO} 144$ \\
\hline 2 & $\begin{array}{l}\text { Aug 11, } 2016 \\
\text { 6:15-9:00 LT }\end{array}$ & 30 & 16 & 8 & $2.8 \mathrm{~km}$ & $\mathrm{CO} 144$ \\
\hline 3 & $\begin{array}{l}\text { Aug 15, } 2016 \\
\text { 6:10-9:00 LT }\end{array}$ & 30 & 16 & 8 & $4 \mathrm{~km}$ & AENC2, CO011 \\
\hline 4 & $\begin{array}{l}\text { Aug 10, } 2016 \\
7: 35-16: 10 \\
\text { LT }\end{array}$ & 50 & 32 & 2 & $1.7 \mathrm{~km}$ & $\mathrm{CO} 003$ \\
\hline 5 & $\begin{array}{l}\text { Aug 17, } 2016 \\
7: 45-15: 35 \\
\text { LT }\end{array}$ & 50 & 16 & 1 & $1.5 \mathrm{~km}$ & CO006 \\
\hline 6 & $\begin{array}{l}\text { Aug 3, } 2016 \\
7: 54-16: 13 \\
\text { LT }\end{array}$ & 50 & 34 & 4 & $1.7 \mathrm{~km}$ & $\mathrm{CO} 003$ \\
\hline BG & $\begin{array}{l}\text { Aug 19, } 2016 \\
7: 45-15: 20 \\
\text { LT }\end{array}$ & 50 & 16 & 1 & $2.6 \mathrm{~km}$ & $\mathrm{CO} 003$ \\
\hline
\end{tabular}

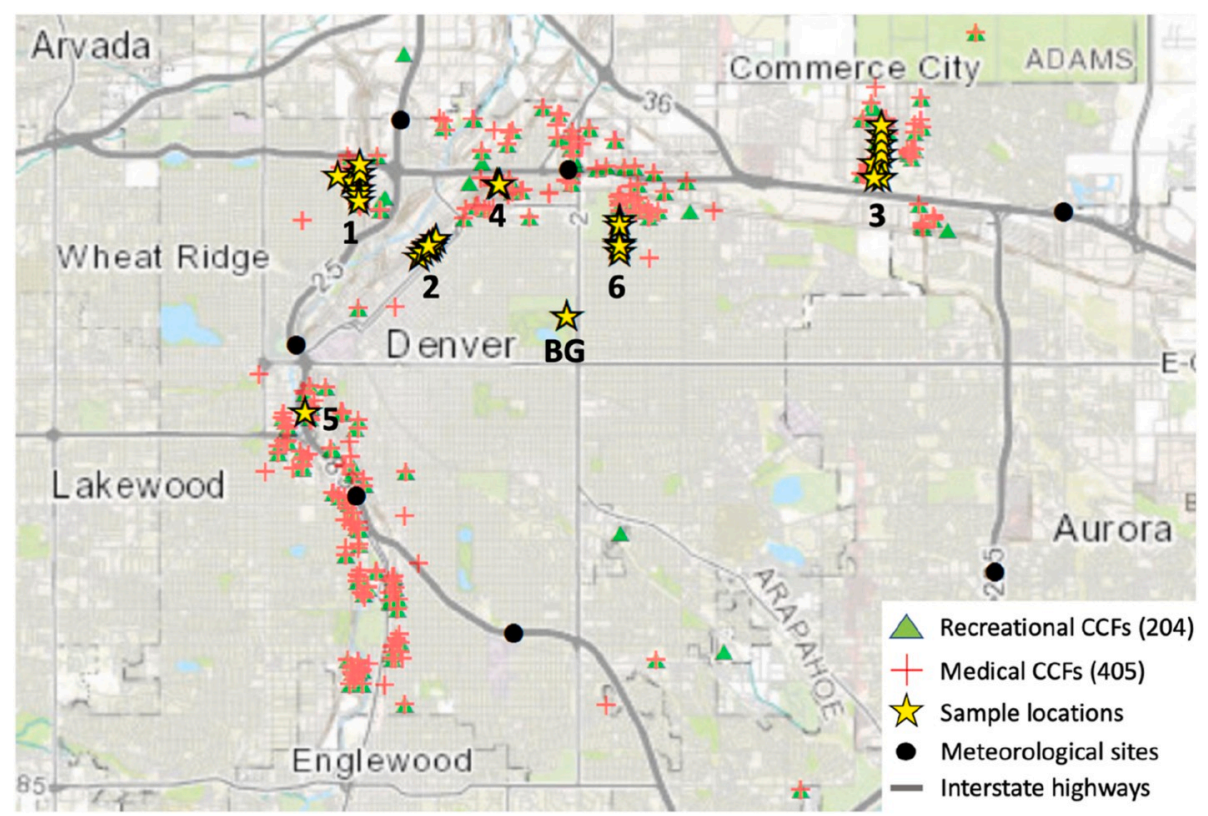

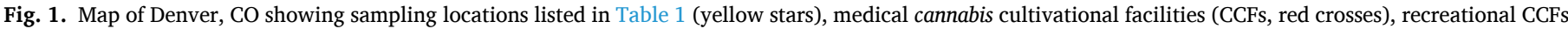

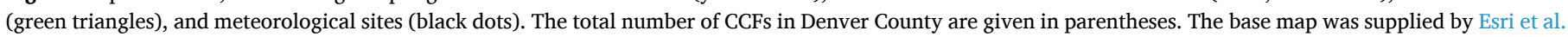
(2013). (For interpretation of the references to colour in this figure legend, the reader is referred to the Web version of this article.)

sources in Denver.

Experiment 6 was motivated by the high number of odour complaints from local Park Hill residents (Murray, 2016; Rusch, 2016). In this experiment samples were taken at two points near CCFs (19 $\mathrm{m}$ and $103 \mathrm{~m}$ ) just to the north of the Park Hill residential area, and at two further points within it ( $433 \mathrm{~m}$ and $655 \mathrm{~m}$ ). Sampling alternated between these sites resulting in 2-hourly, rather than hourly, samples at each.

\subsection{Analysis method and instrument}

Cartridges containing the ambient air samples were thermally desorbed and analyzed by a Gas Chromatograph (GC) (Agilent Technologies, model 7890A) coupled to both a Mass Spectrometer (MS) (model 5975C) and Flame Ionization Detector (FID), following published protocols (Harley et al., 2014). Thermal desorption (TD) was achieved by heating the tubes to $275^{\circ} \mathrm{C}$ in a UNITY TD (model UNITY, Markes International, Llantrisant, UK). The analytes were then focused onto a small cryotrap, which was rapidly heated to $300{ }^{\circ} \mathrm{C}$ and injected on to the GC. Helium was used as the carrier gas in the capillary column (RESTEK Rtx-5 model 10224, $30 \mathrm{~m}, 0.32 \mathrm{~mm}$, ID, $0.25 \mu \mathrm{m}$ film thickness). The GC oven temperature cycle started at $35^{\circ} \mathrm{C}$ and was held at that temperature for $1 \mathrm{~min}$, subsequently increasing at $10^{\circ} \mathrm{C}$ per minute to $260{ }^{\circ} \mathrm{C}$ for each cartridge. Ion fragments and retention time on the column were detected and recorded by MS and FID to optimise capability to distinguish different species present in the sample. To account for changes in MS sensitivity and potential losses during the adsorption and desorption processes, $2 \mathrm{ml}$ of an internal standard (decahydronaphthalene (DHN)), was added to each GC sample. Additional cartridges containing $100 \mathrm{scc}(130 \mathrm{ml}$ at local atmospheric pressure) of a camphene (214.6 ppbv) and isoprene (335 ppbv) gas standard were processed with each experiment for calibration purposes. VOC mixing 
ratios in the sample were deduced by analyzing peak areas and comparing them against those recorded for either camphene $(\mathrm{m} / \mathrm{z}=93)$ or isoprene $(\mathrm{m} / \mathrm{z}=67)$ depending on $\mathrm{m} / \mathrm{z}$ of the detected VOC and correcting for sample volume for each sample.

The analysis method and calculations followed the protocol developed by Harley et al. (2014) for separation and quantification of low-mixing ratio VOCs that elute at similar times. The retention time and major ion fragments for specific VOCs taken from the National Institute of Standards and Technology (NIST) database and a previous study (Harley et al., 2014) were used to distinguish the individual monoterpenes (Table S2). The lower detection limits (LDL) of GC-MS samples are taken to be three standard deviations of blank values. The LDL of terpenes is 4 pptv for a 7-L sample size. Below these limits, non-detected (ND) is reported in the results.

Particular attention was given to distinguishing between d-limonene and $\beta$-phellandrene, which co-elute. Following the procedure of Harley et al. (2014), a second major d-limonene peak at $\mathrm{m} / \mathrm{z}=68$ was used to calculate the mixing ratio of d-limonene and thus accurately determine the mixing ratios of each compound. Fragment ion signals of isoprene $(m / z=67)$ and sesquiterpenes $(m / z=93$ and 133$)$ were also detected in samples by GC-MS, but are not reported here. The isoprene signal at $\mathrm{m} / \mathrm{z}$ $=67$ has a strong co-elution with other (anthropogenic) VOCs at almost identical retention times, and the sesquiterpene fragment signals were not of sufficient magnitude to identify individual sesquiterpenes from the NIST database. Thus, this study only reports specific monoterpene mixing ratios and composition in the samples.

The results show no apparent breakthrough effect in the highflowrate samples with a difference in total monoterpene mixing ratios $< \pm 10 \%$ between the two pump flowrates. All results presented here use only the low-flowrate pump data $(\mathrm{N}=74)$ to avoid system error. In one single case, the low-flowrate cartridge failed to capture the BVOCs, so the high flowrate data was used.

\subsection{Meteorological data and back-trajectory estimate}

Meteorological data for each sampling period were obtained from the National Weather Service (NWS) and Road/Runway Weather Information System (RWIS) networks (Utah, 2019). Wind speed, wind direction, and temperature data from the nearest meteorological station were used to identify the up-wind and down-wind directions and the source locations for the samples, and to estimate back-trajectories. A full list of available weather stations in the vicinity is given in Table S3.

Due to the short life time of monoterpenes in the urban environment, back-trajectories are only calculated for 3-h durations using the approximation given in Eq. (1) (Stohl, 1998; Walmsley and Mailhot, 2010). At each time step, the current air mass location $x$ and $y$ and the $u$ and $v$ downwind and crosswind windspeed vectors from the nearest meteorological site at time $t_{0}$ are used to calculate the previous location $x$ ' and $y^{\prime}$ at time $\mathrm{t}_{0}-\Delta t$. Here, the timestep $\Delta t$ is $5 \mathrm{~min}$. The $u$ and $v$ vectors are calculated from Eq. (2) using the wind direction ( $w w d)$ and wind speed (ws) data from the closest weather station in time to the sampling location.

$\left\{\begin{array}{l}x^{\prime}=x-u\left(x, y, t_{0}\right) \times \Delta t \\ y^{\prime}=y-v\left(x, y, t_{0}\right) \times \Delta t\end{array}\right.$

$\left\{u=w s\left(x, y, t_{0}\right) \times \cos \left(270^{\circ}-w w d\left(x, y, t_{0}\right)\right)\right.$

$\left\{v=w s\left(x, y, t_{0}\right) \times \sin \left(270^{\circ}-w w d\left(x, y, t_{0}\right)\right)\right.$

\section{Results}

\subsection{The ambient monoterpenes mixing ratios and CCFs}

\subsubsection{The monoterpenes mixing ratios and the distance to upwind CCFs}

Table S1 shows the location, sample duration and mixing ratios (pptv) for all individual monoterpenes detected and the total amount of monoterpenes identified for each sample. Total monoterpene mixing ratios ranged from 44 to $926 \mathrm{pptv}$, with the lowest levels found at the BG site (average of $75 \pm 25 \mathrm{pptv}$ from 8 samples). Excluding this site, the average monoterpene mixing ratios were $408 \pm 203$ pptv (from 67 samples). Fig. 2 shows that morning (6:00-11:00 LT) monoterpene mixing ratios are strongly correlated with the distance to the closest upwind CCF $\left(\mathrm{R}^{2}=0.78\right.$, p-value $\ll 0.001$, where the $\mathrm{p}$-value is derived from the null hypothesis in F-test the probability of no relationship between the two variables that we observed). As expected from Gaussian plume dispersion models, mixing ratios decrease as the square of the distance from the source increases. As shown in Fig. 2, mixing ratios at the BG site (2260 m from the nearest CCF) varied between 66 and 116 pptv. By contrast, mixing ratios $>500$ pptv, i.e. approximately 5 times that of BG mixing ratios, were found at distances of 5-100 m downwind of the closest CCF. At a distance of $5 \mathrm{~m}$, the average and standard deviation of mixing ratio were $632 \pm 163 \mathrm{pptv}(\mathrm{N}=5)$; at $12 \mathrm{~m}$, these were $626 \pm 215$ pptv $(\mathrm{N}=8)$, and at $100-200 \mathrm{~m}$, these were $392 \pm 104 \mathrm{pptv}$ $(\mathrm{N}=10)$. The relatively high standard deviations are most likely the result of air parcels intersecting different CCF emission sources prior to measurement. The back-trajectories (Fig. S3) for measurements collected during experiments 1, 2, 4, and 6 show the sampled airmasses passed over numerous CCF clusters that would have contributed to the monoterpenes collected downwind.

Figure S1 presents more details about the relationship of monoterpene and distance to upwind vicinity CCF in different time periods. In Fig. S1A, the early morning (6:00-9:00 LT) hours had the highest monoterpene concentrations and a $\mathrm{R}^{2}$ of 0.82 . The late morning (9:00-12:00 LT) hours had lower mixing ratios but only a slightly lower R-squared of 0.80 (Fig. S1B). Concentrations were lowest in the afternoon samples (12:00-15:00LT) and correlations were also weakest $\left(\mathrm{R}^{2}\right.$ $=0.63$; Fig. S1C). The decreasing monoterpene mixing ratios over the course of the day are most likely attributable to the planetary boundary layer (PBL) height increase during the mid-morning, and more rapid photochemical reactions after noon.

\subsubsection{Experiment 2: the isolated CCF}

Experiment 2, located at the River North Art District, was conducted near an isolated CCF with no other CCFs within $1.5 \mathrm{~km}$. Two replicate samples were taken at each of the different locations simultaneously every $30 \mathrm{~min}$ (6:15-6:45 LT, 6:50-7:20 LT, 7:25-8:05 LT, and 8:30-9:00 LT). There was a total of 8 locations, and 6 of these locations were either directly upwind or downwind of the CCF each time. Fig. 3A shows the sampling time, distance from the CCF (marked by a green diamond) and total monoterpene mixing ratios for each of these 6 sample locations. During this experiment, the windspeed ranged from 0.9 to $2.6 \mathrm{~m} \mathrm{~s}^{-1}$ (average of $1.5 \mathrm{~m} \mathrm{~s}^{-1}$ ) and the average wind direction $\left(211^{\circ} \pm 37^{\circ}\right)$ is indicated by the blue arrow. As expected, total monoterpene mixing ratios were highest at $5 \mathrm{~m}$ downwind of the CCF peaking at $823 \mathrm{ppt}$ and decreased with downwind distance (682 ppt at $107 \mathrm{~m} ; 534 \mathrm{ppt}$ at 239 $\mathrm{m})$. These levels are $\sim 4-7.5$ times higher than the maximum recorded at the BG site (116 pptv). The upwind monoterpene mixing ratio was 410 pptv. The back-trajectory modeling indicated that the closest upwind CCF that could impact experiment 2 (Fig. S3) is $\sim 1.3 \mathrm{~km}$ away, and the large upwind cluster near I-25 is $\sim 4 \mathrm{~km}$ away. Fig. 2 indicates that the monoterpenes decay $\sim 50-70 \%$ within $500 \mathrm{~m}$ of the CCF source. Therefore, the impact of upwind transport of monoterpenes to our experimental site is minimal compared to the local CCF sources.

Fig. 3B shows the monoterpene composition at the closest $(-31 \mathrm{~m}$ and $5 \mathrm{~m}$ ) and farthest $(-282 \mathrm{~m}$ and $239 \mathrm{~m}$ ) distances of upwind $(-)$ and downwind ( + ) sampling locations shown in Fig. 3A. If the sample taken at $5 \mathrm{~m}$ distance from the CCF is representative of the emission flux, it is evident that the fraction of $\beta$-myrcene decreases rapidly with distance. At the same time, $\alpha$ - and $\beta$-pinene, and to a lesser extent camphene and p-cymene comprise increasingly more of the total fraction of monoterpenes. This is consistent with the relative reactivities of the monoterpenes with the highly reactive $\beta$-myrcene oxidizing far more rapidly 


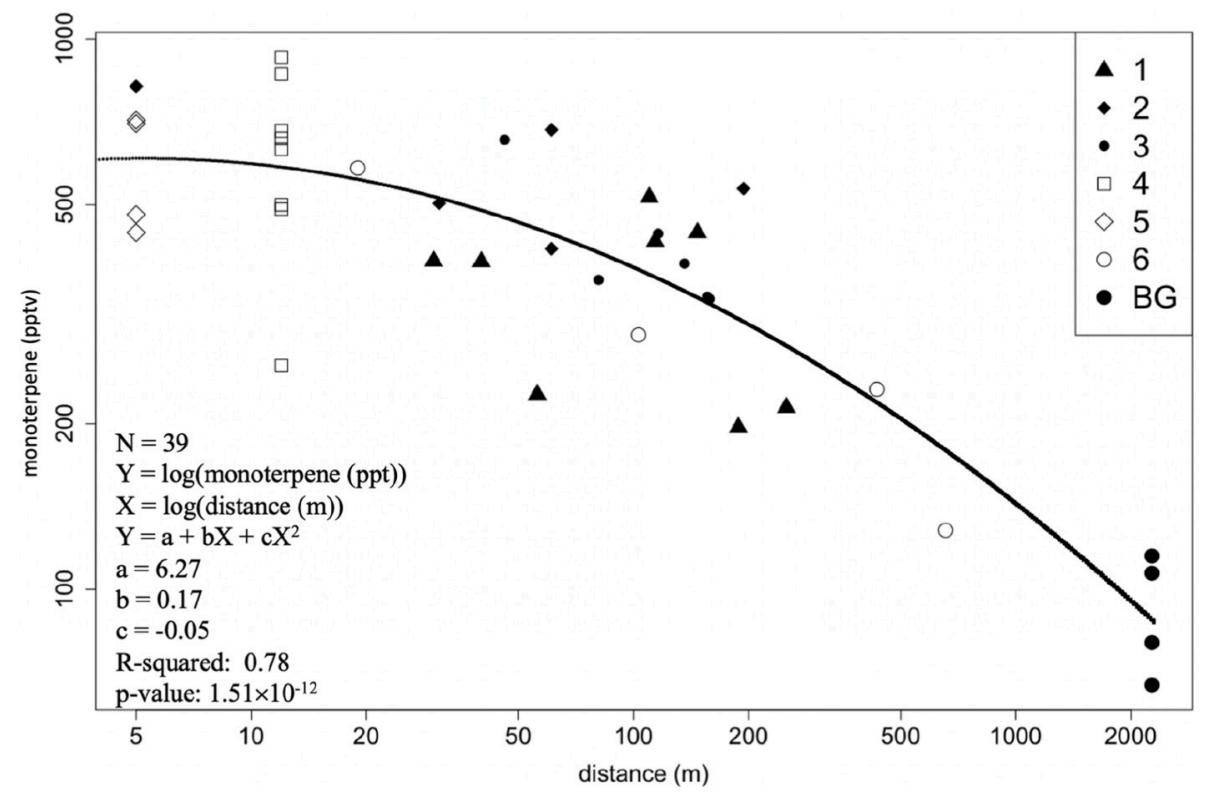

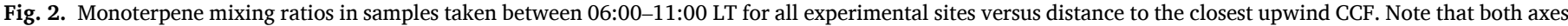

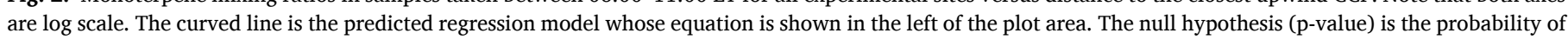
there being no relationship between the two observed variables.

A

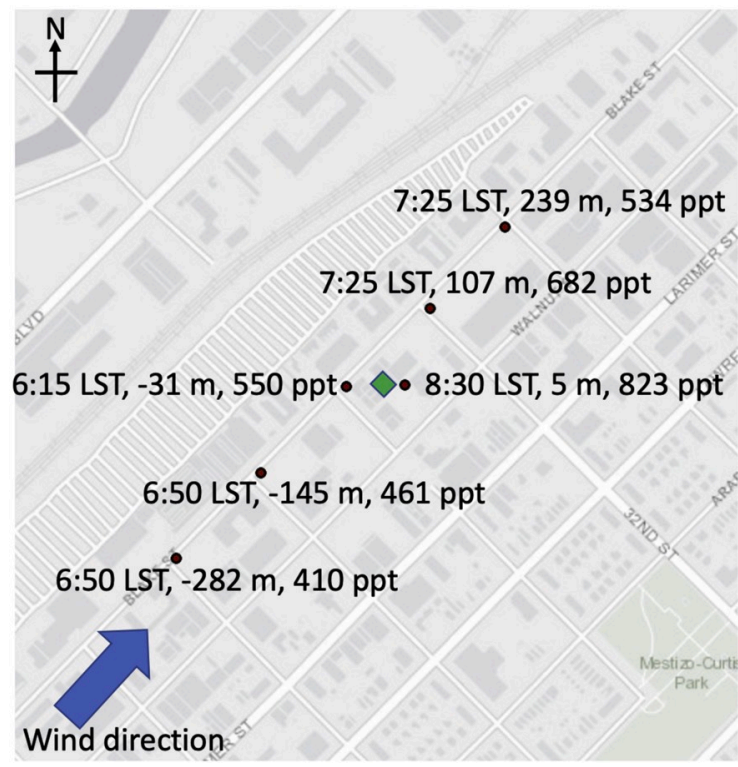

B

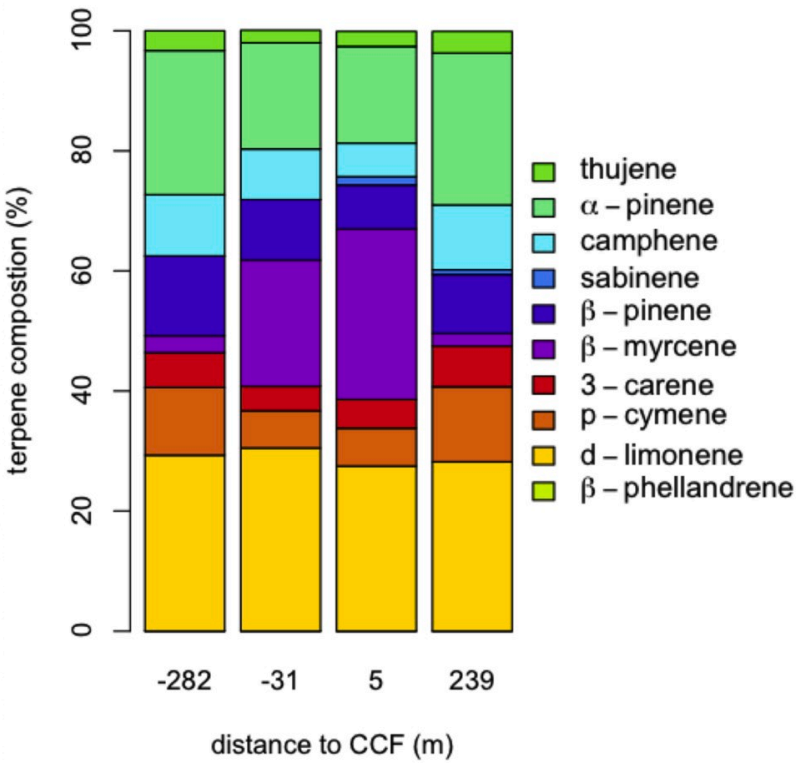

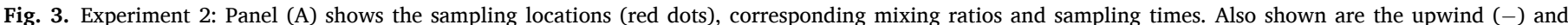

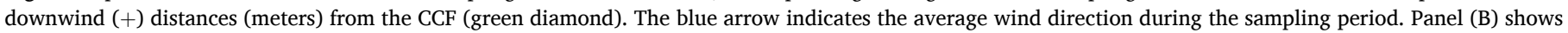

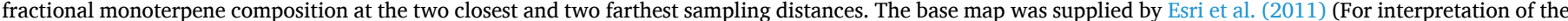
references to colour in this figure legend, the reader is referred to the Web version of this article.)

than the more stable compounds such as $\alpha$ - and $\beta$-pinene. The atmospheric lifetime of $\alpha$-pinene is $\sim 5 \times$ that of $\beta$-myrcene against both the $\mathrm{OH}$ radical and ozone (Hites and Turner, 2009; Hens et al., 2014; Yanez-Serrano et al., 2018).

\subsubsection{Estimating the potential monoterpene source}

The experiment times in this study varied from 6:00-9:00 LT (radial sampling) or 8:00-15:00 LT (diurnal sampling); measurements collected between 8:00-9:00 LT are available for all experiments to compare the mixing ratio at the same time period. At this hour, the samples are least impacted by photochemistry losses that occur later in the day and by dilution with the mid-day development of the PBL. The PBL heights for all experiments were estimated by the HYSPLIT model with HighResolution Rapid Refresh (HRRR) meteorological data (NOAA, 2019) and showed in Fig. S2.

The PBL height is estimated by the model and was not confirmed by measurement data. The differences in surface temperature, however, can provide a possible reason for the PBL height differences. The surface at the BG site is primarily grassland and trees and the surface temperature was about $19-25{ }^{\circ} \mathrm{C}$ at $10: 00-15: 00 \mathrm{LT}$ (Table S1). This is $5-9{ }^{\circ} \mathrm{C}$ 
lower than other experiments $\left(28-34{ }^{\circ} \mathrm{C}\right)$ that were conducted at the more built locations, which resulted in a lower PBL height between 10:00-15:00 LT and reduced the vertical dilution process. Despite the limited dilution and large number of biogenic sources ( $>3000$ trees), monoterpene mixing ratios at the BG site were the lowest measured.

The distance to emission source, wind directions, and photochemistry dominated the ambient monoterpene mixing ratios in our samples and provided an opportunity to investigate the emission source strengths of CCFs upwind of all experimental locations. Fig. 4 shows the average mixing ratios for all experimental sites using only data from times between 8:00-9:00 LT. Taking wind speed and direction data from the closest meteorological site, we estimated 3-h back trajectories at 8:00, 8:30 and 9:00 LT for each of these sites. These are shown in Fig. S3. The back-trajectory paths were analyzed to identify known CCFs located along the pathway that therefore contributed to the air samples taken. The average number of CCFs along each back-trajectory are indicated by grey bars shown in Fig. 4. The 3-h back-trajectories from the BG site (Fig. S3) did not intersect any CCFs, providing confidence that this measurement is not significantly influenced by CCF emissions. The negligible concentrations and absence of marker monoterpenes also lend confidence to our assumption that dispersed and transported monoterpenes from CCF clusters do not significantly impact the mixing ratios recorded at the $\mathrm{BG}$ sampling locations. The wind direction data from the Denver International Airport (DIA) were consistent with the results of the back-trajectories. In Table S4, the meteorological data from DIA also showed that the wind direction in experiments 1-6 were mainly from the southwest and during the BG experiment it wasmainly from theeast.

As the number of Cannabis spp. plants under cultivation in individual CCFs is not publicly available, the relative source strength of each CCF could not be determined. Nevertheless, there was a strong correlation between the maximum measured mixing ratios (of 403-864 pptv) with the number of contributing CCFs in the northern region of Fig. 4. These mixing ratios are $\sim 3-8$ times higher than those at the BG site. Interestingly, experiment 5 had similar total monoterpene mixing ratios as the other experiments, but appeared to be influenced by about 30 CCFs. This could be the result of the number, strain, or growth stage of the plants in those CCFs, or the activities or venting practices at the time of the measurement.

\subsection{Monoterpene composition}

Fig. 4 shows the composition of monoterpenes based on the average of measurements taken from 8:00-9:00 LT at each experimental site within $200 \mathrm{~m}$ of the CCF. Compared to the BG site, the samples taken near CCF clusters had higher proportions of d-limonene (18-35\%), $\alpha$-pinene (16-32\%), p-cymene (6-16\%) and 3-carene (4-12\%), but fractions of $\beta$-pinene and eucalyptol were lower. The dominant monoterpene, however, differed between the CCF sites with $\alpha$ - and $\beta$-pinene (up to $27 \%$ and $17 \%$ ) dominating in the western and north-western part of the Denver County (experiments 1 and 5), and $\beta$-myrcene and dlimonene (up to 20\% and 33\%) in northern of the Denver County (experiments 2 and 4). Experiment 6 at north-eastern part of the city also showed a relatively large proportion of sabinene (12\%), a minor contribution elsewhere. The differences in terpene compositions associated with the different CCF cluster locations suggest a mixture of Cannabis ssp. strains under cultivation across Denver. Thujene, camphene, $\beta$-myrcene, and 3 -carene were observed in the vicinity of CCFs, but were below detection limits at the BG site, suggesting that the monoterpene composition from the Cannabis industry in Denver differs from the other local vegetation, such as landscaping, lawns, trees and gardens.

Fig. 5A shows the composition of monoterpene and terpenoids emissions measured by Wang et al. (2019b) from four Cannabis spp. strains: Critical Mass (CM), Lemon Wheel (LW), Elephant Purple (EP),

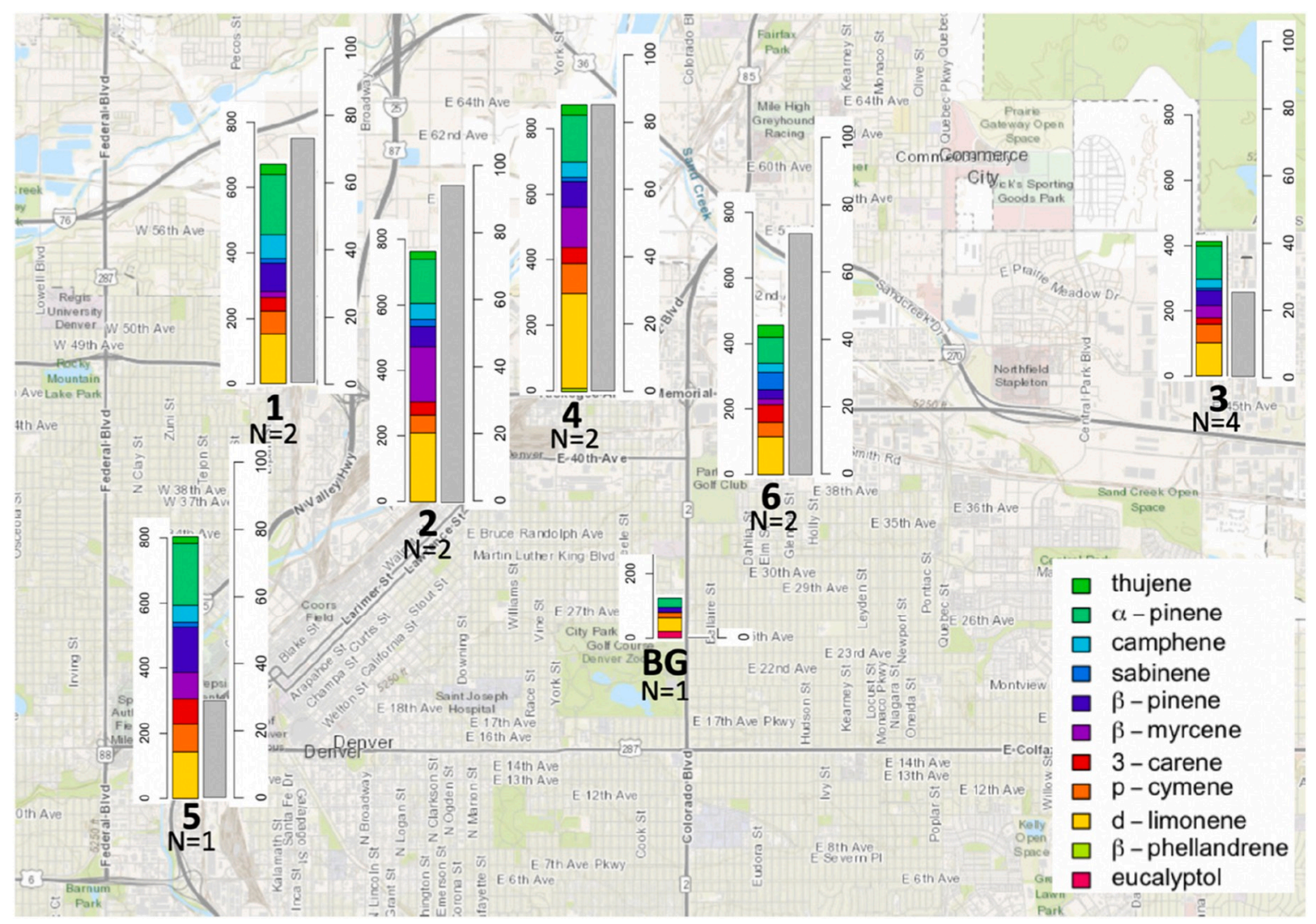

Fig. 4. The average total mixing ratios (pptv) of individual monoterpene and terpenoid, and the number of samples at each experiment between 8:00-9:00 LT. The estimated number of CCFs along the estimated back-trajectories (Fig. S2) are shown by the grey bars. The base map was supplied by Esri et al., 2013. 


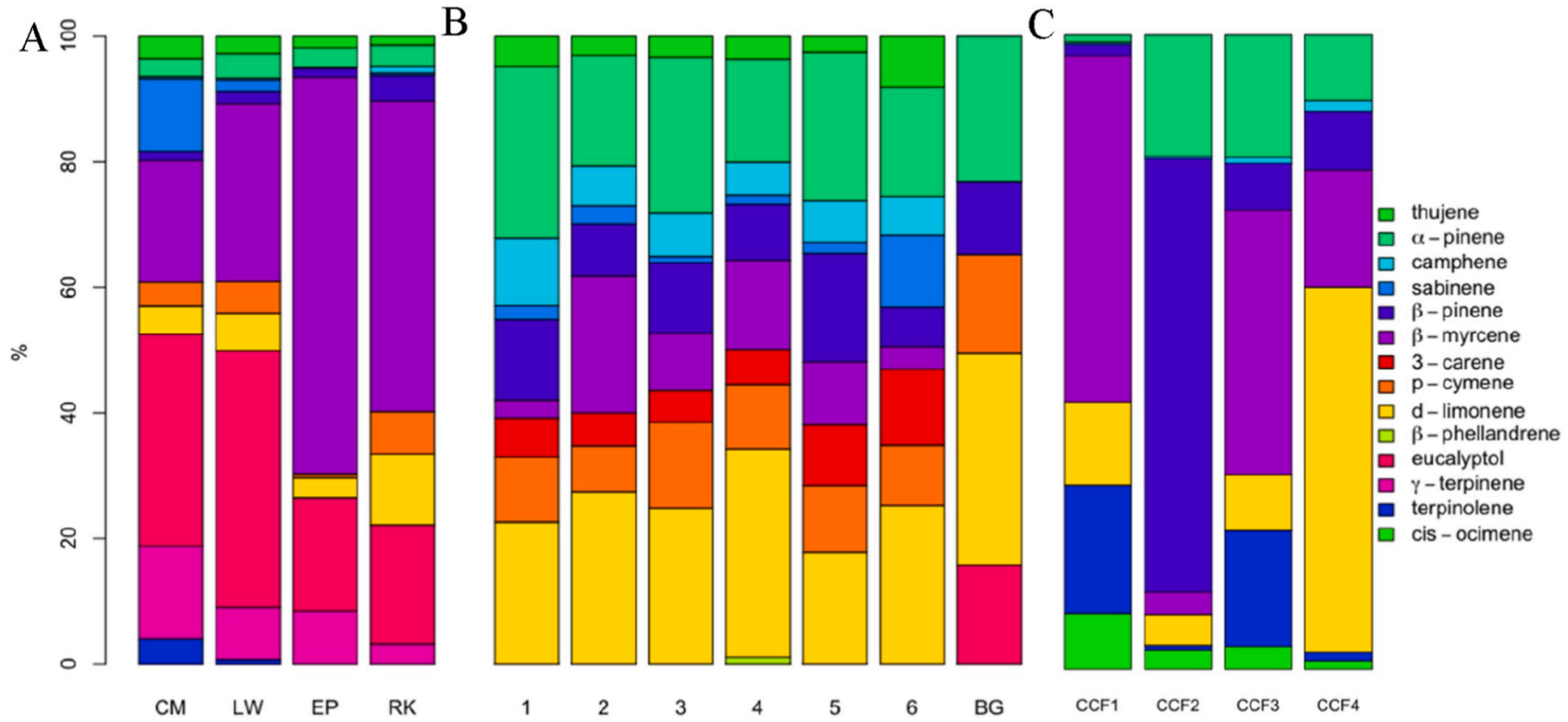

Fig. 5. (A) The monoterpene and terpenoid composition (\%) of emissions from Critical Mass (CM), Lemon Wheel (LW), Elephant Purple (EP), and Rockstar Kush (RK; Wang et al., 2019b). and (B) in ambient air samples taken at experiments 1-6 and BG. (C) The monoterpene composition (\%) in the grow room of four different indoor facilities measured by Samburova et al. (Samburova et al., 2019). (For interpretation of the references to colour in this figure legend, the reader is referred to the Web version of this article.)

and Rockstar Kush (RK). The dominant compounds among these strains were $\beta$-myrcene (20-60\%), eucalyptol (18-40\%) and d-limonene (3\%$10 \%)$. Fig. 5B shows the same data as Fig. 4, but normalized to percentage (\%) for comparison. Comparing the compositions of ambient air and enclosure samples, it appears that $\beta$-myrcene is ubiquitous between strains but absent from background air in Denver (BG site on Fig. 5B) and may therefore be exclusive to Cannabis in an urban context. Interestingly, the proportion of sabinene measured at experiment 6 was
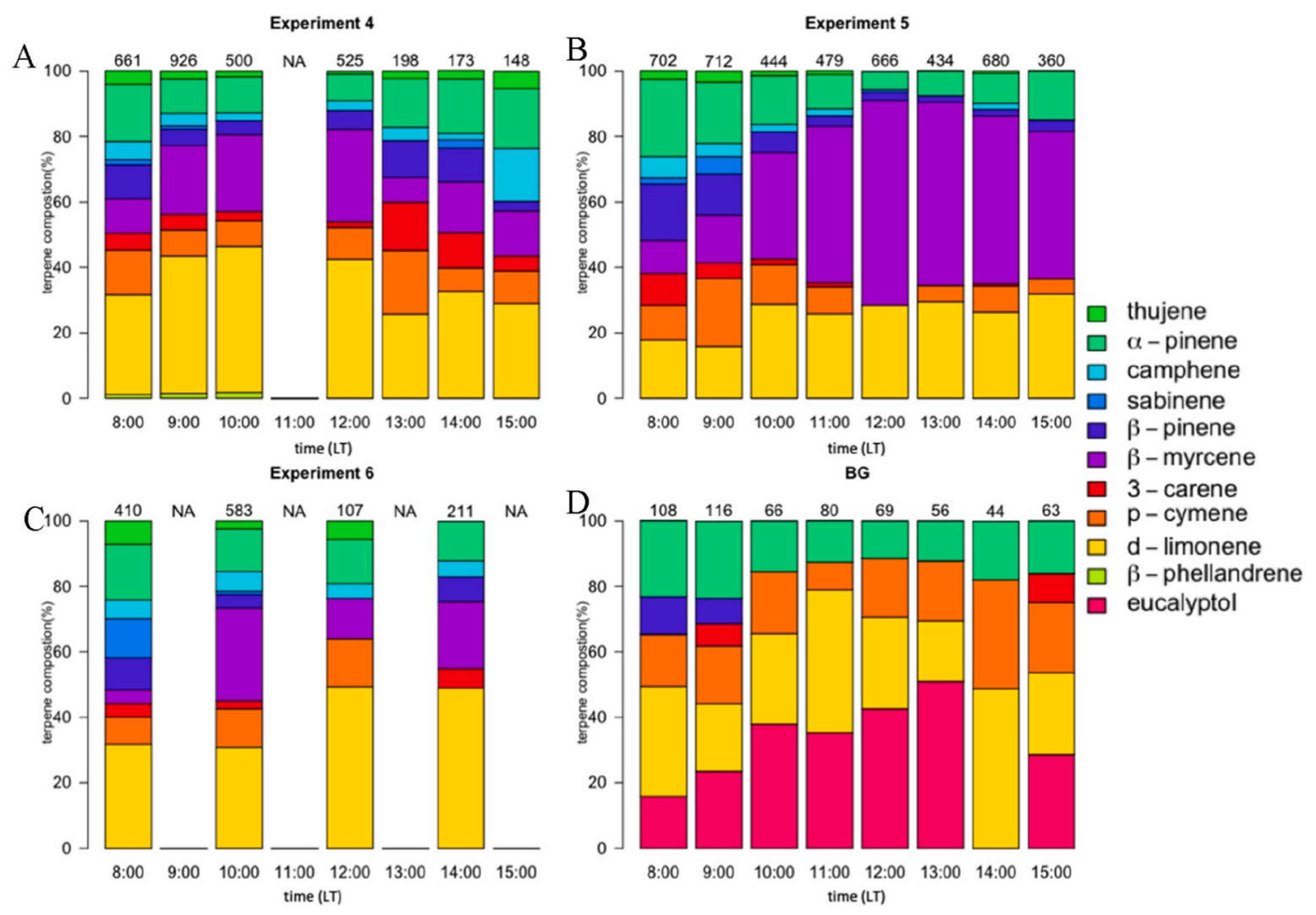

Fig. 6. Monoterpene composition from experiments (A) 4, (B) 5, (C) 6, and (D) background (BG) between 08:00 and 15:00 LT. The numbers on the top of each bar are the total monoterpene mixing ratios (pptv). 
similar to that from the Critical Mass strain (Wang et al., 2019b).

Fig. 5C presents monoterpene compositions measured in indoor grow rooms of four different CCFs in the US states of California and Nevada (Samburova et al., 2019). Their results indicate that different monoterpene compounds dominate in each of the CCFs: $\beta$-myrcene (CCF 1: $55 \%$ and 3: 42\%), $\beta$-pinene (CCF 2: 68\%), and d-limonene (CCF 4: $58 \%$ ) as the composition of BVOCs emitted from Cannabis spp. varies by result may explain the reason for the lack of eucalyptol found in the ambient environment despite being seen in direct emissions from all four strains tested by Wang et al. (2019b). $\beta$-myrcene was detected in all samples from Cannabis spp. Fig. 5A-C shows that $\gamma$-terpinene and terpinolene were present in the direct emissions sampled from Cannabis spp. plants and from grow rooms, but were not detected in the ambient measurements.

Fig. 6 show the hourly fractional monoterpene composition for experiments 4-6, and at the BG site from 08:00-15:00 LT. Total mixing ratios are reported at the top of each bar and Fig. S4. Peak mixing ratios were recorded at 09:00 LT at all experiments (10:00 LT at experiment 6 which was only sampled 2-hourly). Mixing ratios in all diurnal experiments (4-6 and BG) generally decrease in the afternoon due to increasing PBL height and photochemical losses. Experiment 5 is an anomaly to this pattern as secondary peaks occur at 12:00 and 14:00 LT. It may be that the relatively constant mixing ratios seen at experiment 5 were due to the close proximity of the sampling to the ventilation outlet of the CCF $(\sim 5 \mathrm{~m})$ Inside CCFs, the environment is typically maintained at constant conditions of light, temperature and $\mathrm{CO}_{2}$ concentrations, but other activities such as plant movement, harvesting, trimming and air handling can contribute to how emissions are vented into the ambient atmosphere.

The monoterpene fractional compositions of experiments 4 and 5 also changed with time. In experiment 5 , the fraction of $\beta$-myrcene was $10 \%$ at $8: 00 \mathrm{LT}$, increased to $62 \%$ at noon, and then decreased to $45 \%$ by 15:00 LT. Experiment 4 showed a similar pattern in that d-limonene and $\beta$-myrcene were low in the morning, but increased to their peak mixing ratios at noon. This mid-day increase at noon cannot be explained by strain, growth stage, growth environment and agronomic practice. This

photochemistry, as $\beta$-myrcene and d-limonene have higher rate constants (shorter lifetimes) than $\alpha$-pinene and $\beta$-pinene at ambient conditions. Thus, this could be the result of compositional changes at the emission source. Some previous laboratory and field studies have shown that the monoterpene emission fraction from a plant are known to be environmental condition dependent, such as light, temperature and insect (Sharkey et al., 1991; Staudt et al., 1997; Jones et al., 2011; Yanez-Serrano et al., 2018), but the Cannabis plants in this study is unknown.

The experiments 6 and BG show different monoterpene speciation with time. The fraction of d-limonene in experiment 6 was $\sim 30 \%$ between 8:00 and 10:00 LT, and increased to $50 \%$ between noon and 14:00 LT. $\beta$-myrcene only accounted for $4 \%$ of monoterpenes at 8:00 LT, but increased to $28 \%$ by $10: 00$ LT. At noon, $\beta$-myrcene decreased to $12 \%$ then increased to $20 \%$ at $14: 00$ LT. At the BG site, the fraction of eucalyptol at 8:00 LT was $16 \%$, but increased up to $50 \%$ at 13:00 LT. The eucalyptol fraction increase may be caused by the longer lifetime of eucalyptol when compared to most other monoterpenes (Medcraft and Schnell, 2016; Roldin et al., 2015).

\subsection{Comparison with air quality model predictions}

Fig. 7 shows the comparison for measured and modeled hourly monoterpene mixing ratios. Measured data from experiments 1-6 (taken between 06:00-15:00 LT) are shown as red box plots with the BG samples (taken between 08:00-15:00 LT) shown as green dots. In the early morning hours (6:00-9:00 LT) median mixing ratios of the sum of all monoterpenes were 444-505 pptv, with an interquartile range (IQR; Q3-Q1) of 135-282 pptv. After 10:00 LT, monoterpene mixing ratios decreased, initially due to the dilution effect of the evolution of the PBL and then from an increase in photochemical loss rates. By contrast, experiment 5 exhibited two peaks of 668 and 680 pptv at 12:00-13:00 LT and 14:00-15:00 LT. This is likely due to the location of experiment 5 being the closest one to CCF ventilation outlets $(\sim 5 \mathrm{~m})$, and thus preventing chemical loss or dilution prior to sampling.

We previously reported simulated monoterpene mixing ratios across

\section{A}

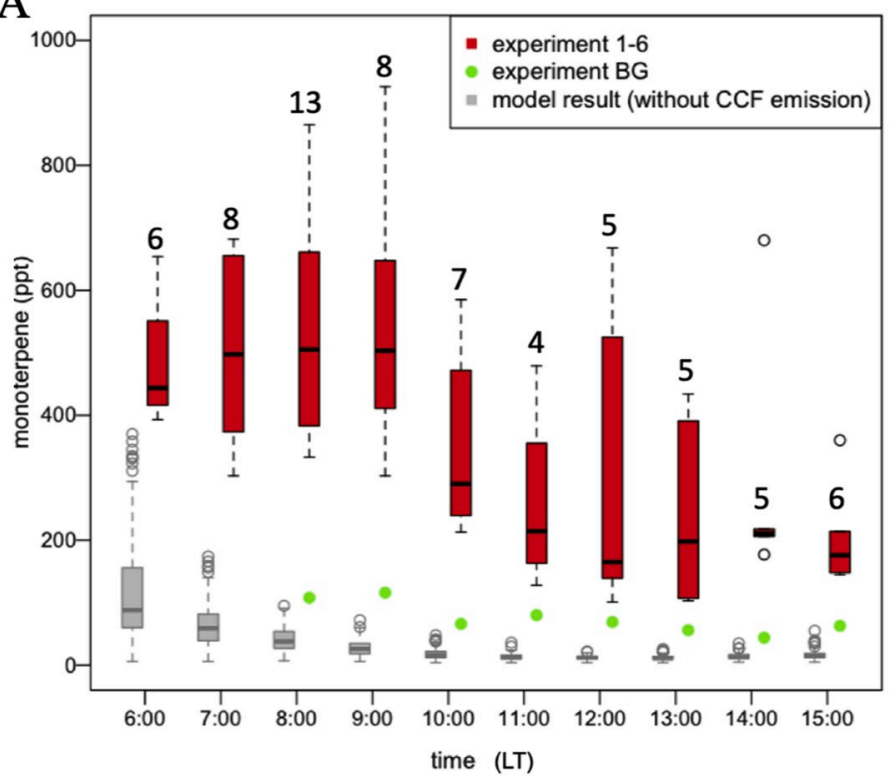

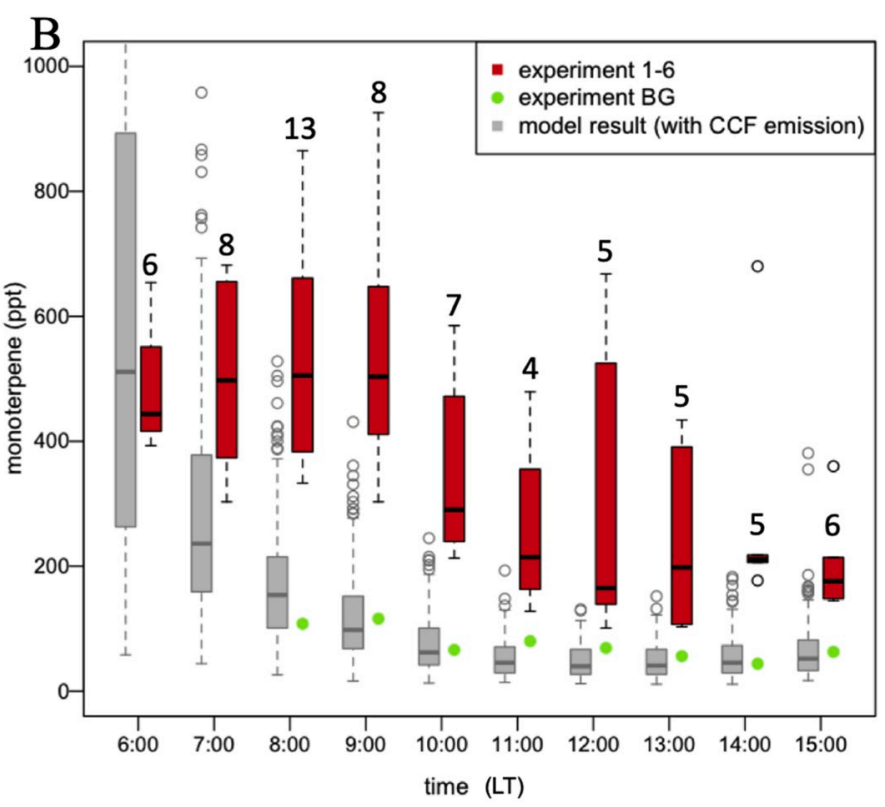

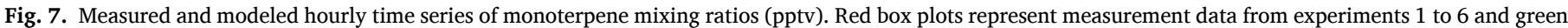

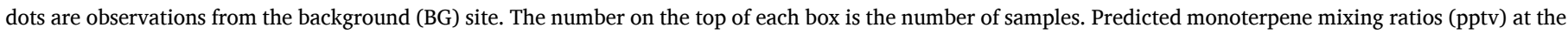

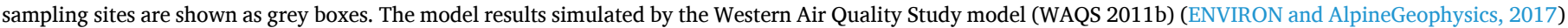

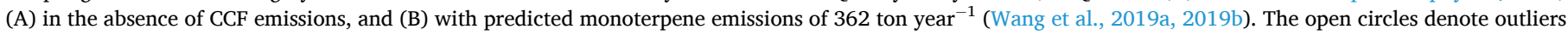

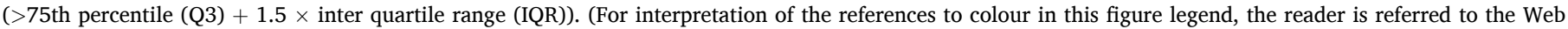
version of this article.) 
Denver County using the Western Air Quality Study model (ENVIRON and AlpineGeophysics, 2017) that included estimated CCF emissions as model inputs (Wang et al., 2019a, 2019b). Although the episode modeled used meteorology from 2011 in contrast to this study in 2016, it still provided a qualitative comparison between predictions from an estimated inventory and real-world measurements. Fig. 7A and B compare modeled hourly mixing ratios in August 2011 (with and without CCF emissions respectively) shown as grey box plots with those measured in 2016. As shown in Fig. 7A, the median mixing ratio from simulations without CCF emissions was 88 pptv at 06:00 LT and $12 \mathrm{pptv}$ at 12:00 LT across all relevant grid cells, which is lower than the observations from the BG site (median $=67.5$ and $\mathrm{IQR}=34.5$ ). When Denver CCF emissions of 362 tons year ${ }^{-1}$ were included in the model (Fig. 7B), the median rose to $511 \mathrm{pptv}$ at 06:00 LT, which is similar to the median of the samples collected at CCF sites at 06:00 LT (444 pptv), and the estimated concentration of $40 \mathrm{pptv}$ at 12:00 LT is similar to the 69 pptv recorded from BG samples at noon. This estimated concentration is somewhat lower than observations taken in the vicinity of CCF clusters at 12:00 LT (165 pptv). Grid cell concentrations from air quality models are an average across the full area and does not account for spatial heterogeneity and must by definition always underestimate peaks and overestimate background levels (i.e. those locations far away from sources).

\section{Conclusion}

This is the first study to provide evidence of elevated outdoor mixing ratios of monoterpenes in the vicinity of CCFs in Denver where the Cannabis industry is legalized. The results showed total monoterpene mixing ratios are $\sim 4-8$ times higher around CCFs than observed at a background location. Monoterpene mixing ratios decreased $\sim 1.5 \mathrm{pptv}$ per meter distance away from each individual CCF. While the total number of CCFs within $500 \mathrm{~m}$ strongly correlated with measured mixing ratios, some clusters of CCFs had higher than expected mixing ratios in the vicinity. This is likely due to differences in emission source strengths due to differences in the number, strain and growth stage of plants, and crop management activities taking place in each CCF. This information is currently unavailable to the research community and could not be used in this study. Analysis of monoterpene composition showed geographic variability suggesting that different clusters of CCFs may have different monoterpene emission profiles due to variability in strains or life cycle. One monoterpene, $\beta$-myrcene, was identified in samples taken downwind of CCFs but this was not detected in background measurements at a site remote from CCFs. Since $\beta$-myrcene and its oxidized products have been measured in leaf enclosure studies and inside CCFs, this suggests it could be a potential tracer for CCF emissions in the ambient environment (Boge et al., 2013).

The sampling studies reported here were limited in both time and space. Future campaigns across more sample locations and during different seasons would be beneficial to better understanding the impact CCF emissions have on terpene mixing ratios in Denver. Our study, however, clearly demonstrates that emissions from growing Cannabis spp. are detectable at measurable mixing ratios at distance from CCFs, suggesting this single industry strongly influences the composition of the urban atmosphere in Denver. Given the fairly unique "signature" of compounds from Cannabis spp. and the proximity to clusters of CCFs we are confident that the VOCs we sampled did indeed originate from CCFs.

\section{Discussion}

Our findings suggest that the introduction and rapid growth of previously niche industries (e.g. artisan coffee roasters, craft breweries, etc. that are highly odiferous) can also be expected to have similar impacts. Recent studies (McDonald et al., 2018; Shah et al., 2019) have also shown that volatile chemical products (VCPs), such as acetone, chlorinated hydrocarbons, monoterpenes and aldehydes, in household cleaning and personal care products affect VOC mixing ratios in urban areas. Some VCPs, such as d-limonene, are highly reactive and have short atmospheric lifetimes. Those highly reactive species are easily transformed to secondary pollutants in urban areas. McDonald et al. reported that monoterpenes mixing ratios in indoors measurement in Los Angeles were 7-9 ppb, which is higher than observed in a pine forest in Colorado (Ortega et al., 2014) but lower than those measured in indoor CCFs (20-1000 ppb) (Samburova et al., 2019). Another urban ambient measurement study in New York City recorded elevated concentrations of monoterpene and other VCPs in excess of $3.5 \mathrm{ppb}$ (Shah et al., 2019). A WHO report (Simpson and Volosciuk, 2019) concluded that due to decreasing traffic VOCs in cities, non-traffic VOC sources are becoming relatively more important for ozone and SOA formation. Therefore, we suggest a need for more studies and better understanding. This could create a broader knowledge base that would be useful in predicting the impacts of CCFs on secondary air pollutants.

\section{Declaration of competing interest}

The authors declare that they have no known competing financial interests or personal relationships that could have appeared to influence the work reported in this paper.

\section{CRediT authorship contribution statement}

Chi-Tsan Wang: Conceptualization, Data curation, Formal analysis, Investigation, Methodology, Software, Visualization, Writing - original draft, Writing - review \& editing. Kirsti Ashworth: Supervision, Conceptualization, Data curation, Methodology, Investigation, Validation, Writing - original draft, Writing - review \& editing. Christine Wiedinmyer: Supervision, Conceptualization, Data curation, Funding acquisition. John Ortega: Data curation, Software, Validation, Resources, Methodology, Writing - original draft, Writing - review \& editing. Peter C. Harley: Methodology, Resources. Quazi Z. Rasool: Conceptualization, Software. William Vizuete: Project administration, Data curation, Supervision, Validation, Funding acquisition, Writing original draft, Writing - review \& editing.

\section{Acknowledgments}

We would like to thank the National Center for Atmospheric Research (NCAR) Advanced Study Program (ASP) for their support of Chi-Tsan Wang and the Atmospheric Chemistry Observations and Modeling (ACOM) Laboratory for supplying the adsorbent cartridges, sampling equipment and access to the GC-MS/FID. NCAR's involvement in this study was limited to the measurement of ambient air near the Cannabis cultivation facilities and did not involve the manufacture, import, possession, use or distribution of Cannabis. The National Center for Atmospheric Research is sponsored by the National Science Foundation. Any opinions, findings and conclusions or recommendations expressed in this material do not necessarily reflect the views of the National Science Foundation. We also thank Dr. Feng-Chi Hsu, Dr. Jason Surratt, Dr. Yue Zhang, Ling Chun Yeh, and Grant Josenhans for their invaluable assistance.

\section{Appendix A. Supplementary data}

Supplementary data to this article can be found online at https://doi. org/10.1016/j.atmosenv.2020.117510.

\section{References}

Acton, W.J.F., Schallhart, S., Langford, B., Valach, A., Rantala, P., Fares, S., Carriero, G., Tillmann, R., Tomlinson, S.J., Dragosits, U., Gianelle, D., Hewitt, C.N., Nemitz, E., 2016. Canopy-scale flux measurements and bottom-up emission estimates of volatile organic compounds from a mixed oak and hornbeam forest in northern Italy. Atmos. Chem. Phys. 16, 7149-7170. https://doi.org/10.5194/acp-16-7149-2016. 
Boge, O., Mutzel, A., Iinuma, Y., Yli-Pirila, P., Kahnt, A., Joutsensaari, J., Herrmann, H., 2013. Gas-phase products and secondary organic aerosol formation from the ozonolysis and photooxidation of myrcene. Atmos. Environ. 79, 553-560. https:// doi.org/10.1016/j.atmosenv.2013.07.034.

CDOR, 2018. Licensees - marijuana enforcement division. https://www.colorado gov/pacific/enforcement/med-licensed-facilities. (Accessed 2 May 2019).

City and County of Denver, 2019. Denver parks and recreation. https://www.denvergov. org/content/denvergov/en/denver-parks-and-recreation/trees-natural-resources /forestry-trees-.html. (Accessed 10 March 2020).

Emmerson, K.M., Galbally, I.E., Guenther, A.B., Paton-Walsh, C., Guerette, E.A., Cope, M. E., Keywood, M.D., Lawson, S.J., Molloy, S.B., Dunne, E., Thatcher, M., Karl, T., Maleknia, S.D., 2016. Current estimates of biogenic emissions from eucalypts uncertain for southeast Australia. Atmos. Chem. Phys. 16, 6997-7011. https://doi org/10.5194/acp-16-6997-2016.

ENVIRON, and AlpineGeophysics. Denver Metro/North Front Range 2017 8-Hour Ozone State Implementation Plan: 2017 Attainment Demonstration Modeling Final Report, Regional Air Quality Council. available at: http://views.cira.colostate. edu/wiki/Attachments/Source\% 20Apportionment/Denver/Denver_2017SIP_2017AttainDemo_Finalv1.pdf 2017.

Esri, HERE, Garmin, OpenStreetMap contributors, the GIS User Community, 2011. World Light Gray Canvas Base.

Esri, Here, TomTom, Intermap, increment P Corp, GEBCO, USGS, FAO, NPS, NRCAN, GeoBase, IGN, Kadaster NL, Ordnance Survey, Esri Japan, METI, Esri China (Hong Kong), swisstopo, MapmyIndia, the GIS User Community, 2013. World Topographic Map.

Guenther, A., Hewitt, C.N., Erickson, D., Fall, R., Geron, C., Graedel, T., Harley, P., Klinger, L., Lerdau, M., McKay, W.A., Pierce, T., Scholes, B., Steinbrecher, R., Tallamraju, R., Taylor, J., Zimmerman, P., 1995. A global-model OF natural volatile organic-compound emissions. J. Geophys. Res. Atmosp. 100, 8873-8892. https:// doi.org/10.1029/94jd02950.

Guenther, A., Karl, T., Harley, P., Wiedinmyer, C., Palmer, P.I., Geron, C., 2006. Estimates of global terrestrial isoprene emissions using MEGAN (model of emissions of gases and aerosols from nature). Atmos. Chem. Phys. 6, 3181-3210.

Harley, P., Eller, A., Guenther, A., Monson, R.K., 2014. Observations and models of emissions of volatile terpenoid compounds from needles of ponderosa pine trees growing in situ: control by light, temperature and stomatal conductance. Oecologia 176, 35-55. https://doi.org/10.1007/s00442-014-3008-5.

Hartman, M., Humphreys, H., Burack, J., Lambert, K., Martin, P., Colorado Department of Revenue. MED 2018 Mid-year Update. available at: https://www.colorado. gov/pacific/sites/default/files/2018\%20Mid\%20Year\%20Update.pdf 2018.

Hens, K., Novelli, A., Martinez, M., Auld, J., Axinte, R., Bohn, B., Fischer, H., Keronen, P., Kubistin, D., Nolscher, A.C., Oswald, R., Paasonen, P., Petaja, T., Regelin, E., Sander, R., Sinha, V., Sipila, M., Taraborrelli, D., Ernest, C.T., Williams, J., Lelieveld, J., Harder, H., 2014. Observation and modelling of HOx radicals in a boreal forest. Atmos. Chem. Phys. 14, 8723-8747. https://doi.org/10.5194/acp-148723-2014.

Hites, R.A., Turner, A.M., 2009. Rate constants for the gas-phase beta-myrcene plus $\mathrm{OH}$ and isoprene plus $\mathrm{OH}$ reactions as a function of temperature. Int. J. Chem. Kinet. 41 407-413. https://doi.org/10.1002/kin.20413.

Hood, L.V.S., Dames, M.E., Barry, G.T., 1973. Headspace volatiles of marijuana. Nature 242, 402-403.

IWDW, 2017. Emissions review tool. http://views.cira.colostate.edu/tsdw/Emissions /ReviewTool.aspx.

Jones, C.E., Hopkins, J.R., Lewis, A.C., 2011. In situ measurements of isoprene and monoterpenes within a south-east Asian tropical rainforest. Atmos. Chem. Phys. 11, 6971-6984. https://doi.org/10.5194/acp-11-6971-2011.

Martyny, J.W., Serrano, K.A., Schaeffer, J.W., Van Dyke, M.V., 2013. Potential exposures associated with indoor marijuana growing operations. J. Occup. Environ. Hyg. 10, 622-639. https://doi.org/10.1080/15459624.2013.831986.

McDonald, B.C., de Gouw, J.A., Gilman, J.B., Jathar, S.H., Akherati, A., Cappa, C.D., Jimenez, J.L., Lee-Taylor, J., Hayes, P.L., McKeen, S.A., Cui, Y.Y., Kim, S.W., Gentner, D.R., Isaacman-VanWertz, G., Goldstein, A.H., Harley, R.A., Frost, G.J., Roberts, J.M., Ryerson, T.B., Trainer, M., 2018. Volatile chemical products emerging as largest petrochemical source of urban organic emissions. Science 359, 760-764. https://doi.org/10.1126/science.aaq0524.

McPartland, J.M., Russo, E.B., 2001. Cannabis and cannabis extracts: greater than the sum of their parts? J. Cannabis Ther. 1, 103-132. https://doi.org/10.1300/ J175v01n03 08.

Medcraft, C., Schnell, M., 2016. A comparative study of two bicyclic ethers, eucalyptol and 1,4-cineole, by broadband rotational spectroscopy. Z. Phys. Chemie-Int. J. Res. Phys. Chem. Chem. Phys. 230, 1-14. https://doi.org/10.1515/zpch-2015-0643.

Murray, J., 2016. The marijuana industry's war on the poor. https://www.politico. com/magazine/story/2016/05/what-works-colorado-denver-marijuana-pot-industr y-legalization-neighborhoods-dispensaries-negative-213906.

NOAA, 2019. Hysplit. https://www.ready.noaa.gov/HYSPLIT.php. (Accessed 5 January 2020).

Ortega, J., Helmig, D., 2008. Approaches for quantifying reactive and low-volatility biogenic organic compound emissions by vegetation enclosure techniques - Part A Chemosphere 72, 343-364. https://doi.org/10.1016/j.chemosphere.2007.11.020.

Ortega, J., Helmig, D., Daly, R.W., Tanner, D.M., Guenther, A.B., Herrick, J.D., 2008. Approaches for quantifying reactive and low-volatility biogenic organic compound emissions by vegetation enclosure techniques - Part B: Applications. Chemosphere 72, 365-380. https://doi.org/10.1016/j.chemosphere.2008.02.054.

Ortega, J., Turnipseed, A., Guenther, A.B., Karl, T.G., Day, D.A., Gochis, D., Huffman, J. A., Prenni, A.J., Levin, E.J.T., Kreidenweis, S.M., DeMott, P.J., Tobo, Y., Patton, E.G., Hodzic, A., Cui, Y.Y., Harley, P.C., Hornbrook, R.S., Apel, E.C., Monson, R.K., Eller, A.S.D., Greenberg, J.P., Barth, M.C., Campuzano-Jost, P., Palm, B.B., Jimenez, J.L., Aiken, A.C., Dubey, M.K., Geron, C., Offenberg, J., Ryan, M.G., Fornwalt, P.J., Pryor, S.C., Keutsch, F.N., DiGangi, J.P., Chan, A.W.H., Goldstein, A. H., Wolfe, G.M., Kim, S., Kaser, L., Schnitzhofer, R., Hansel, A., Cantrell, C.A., Mauldin, R.L., Smith, J.N., 2014. Overview of the Manitou Experimental Forest Observatory: site description and selected science results from 2008 to 2013. Atmos. Chem. Phys. 14, 6345-6367. https://doi.org/10.5194/acp-14-6345-2014.

Pollmann, J., Ortega, J., Helmig, D., 2005. Analysis of atmospheric sesquiterpenes: sampling losses and mitigation of ozone interferences. Environ. Sci. Technol. 39, 9620-9629. https://doi.org/10.1021/es050440w.

Rice, S., Koziel, J.A., 2015. Characterizing the smell of marijuana by odor impact of volatile compounds: an application of simultaneous chemical and sensory analysis. PloS One 10, 17. https://doi.org/10.1371/journal.pone.0144160.

Roldin, P., Liao, L., Mogensen, D., Dal Maso, M., Rusanen, A., Kerminen, V.M., Mentel, T. F., Wildt, J., Kleist, E., Kiendler-Scharr, A., Tillmann, R., Ehn, M., Kulmala, M., Boy, M., 2015. Modelling the contribution of biogenic volatile organic compounds to new particle formation in the Julich plant atmosphere chamber. Atmos. Chem. Phys. 15, 10777-10798. https://doi.org/10.5194/acp-15-10777-2015.

Ross, S.A., ElSohly, M.A., 1996. The volatile oil composition of fresh and air-dried buds of Cannabis sativa. J. Natl. Proc. 59, 49-51. https://doi.org/10.1021/np960004a.

Rusch, E., 2016. Marijuana-infused neighbor conflicts: ways to clear the air. https:// www.denverpost.com/2014/04/11/marijuana-infused-neighbor-conflicts-ways-toclear-the-air/.

Samburova, V., McDaniel, M., Campbell, D., Wolf, M., Stockwell, W.R., Khlystov, A., 2019. Dominant volatile organic compounds (VOCs) measured at four Cannabis growing facilities: pilot study results. J. Air Waste Manag. Assoc. 1-10. https://doi. org/10.1080/10962247.2019.1654038.

Seinfeld, J.H., Pandis, S.N., 2006. Atmospheric Chemistry and Physics: from Air Pollution to Climate Change.

Shah, R.U., Coggon, M.M., Gkatzelis, G.I., McDonald, B.C., Tasoglou, A., Huber, H., Gilman, J., Warneke, C., Robinson, A.L., Presto, A.A., 2019. Urban oxidation flow reactor measurements reveal significant secondary organic aerosol contributions from volatile emissions of emerging importance. Environ. Sci. Technol. https://doi. org/10.1021/acs.est.9b06531.

Sharkey, T.D., Holland, E.A., Mooney, H.A., 1991. Trace Gas Emissions by Plants.

Simpson, I., Volosciuk, C., 2019. Changing volatile organic compound emissions in urban environments: many paths to cleaner air. https://public.wmo.int/en/resources/bull etin/changing-volatile-organic-compound-emissions-urban-environments-manypaths. (Accessed 15 March 2020).

Southwellb, J., Wena, M., Jobsona, B., 2017. Thomas Spokane Regional Clean Air Agent (SRCAA) Marijuana Air Emissions Sampling \& Testing Project. Inland Northwest Chapter AWMA, Washington State. Oct, 2017.

Staudt, M., Bertin, N., Hansen, U., Seufert, G., Ciccioli, P., Foster, P., Frenzel, B., Fugit, J. L., 1997. Seasonal and diurnal patterns of monoterpene emissions from Pinus pinea (L.) under field conditions. Atmos. Environ. 31, 145-156. https://doi.org/10.1016/ s1352-2310(97)00081-2.

Stohl, A., 1998. Computation, accuracy and applications of trajectories - a review and bibliography. Atmos. Environ. 32, 947-966. https://doi.org/10.1016/s1352-2310 (97)00457-3.

Turner, C.E., Elsohly, M.A., Boeren, E.G., 1980. Constituents OF cannabis-sativa L .17. A review OF the natural constituents. J. Natl. Proc. 43, 169-234. https://doi.org/ 10.1021/np50008a001.

USEPA, 1999. Compendium of Methods for the Determination of Toxic Organic Compounds in Ambient Air. USEPA.

Utah, U.o.. MesoWest. https://mesowest.utah.edu. (Accessed 9 August 2019).

Walmsley, J.L., Mailhot, J., 2010. On the numerical accuracy of trajectory models for long-range transport of atmospheric pollutants. Atmos.-Ocean 21, 14-39. https:// doi.org/10.1080/07055900.1983.9649153.

Wang, C.-T., Wiedinmyer, C., Ashworth, K., Harley, P.C., Ortega, J., Rasool, Q.Z., Vizuete, W., 2019. Potential regional air quality impacts of cannabis cultivation facilities in denver, Colorado. Atmos. Chem. Phys. 19, 13973-13987. https://doi. org/10.5194/acp-19-13973-2019.

Wang, C.-T., Wiedinmyer, C., Ashworth, K., Harley, P.C., Ortega, J., Vizuete, W., 2019b. Leaf Enclosure Measurements for Determining Volatile Organic Compound Emission Capacity from Cannabis Spp. https://doi.org/10.1016/j.atmosenv.2018.10.049.

Yanez-Serrano, A.M., Nolscher, A.C., Williams, J., Wolff, S., Alves, E., Martins, G.A., Bourtsoukidis, E., Brito, J., Jardine, K., Artaxo, P., Kesselmeier, J., 2015. Diel and seasonal changes of biogenic volatile organic compounds within and above an Amazonian rainforest. Atmos. Chem. Phys. 15, 3359-3378. https://doi.org/ 10.5194/acp-15-3359-2015.

Yanez-Serrano, A.M., Nolscher, A.C., Bourtsoukidis, E., Alves, E.G., Ganzeveld, L., Bonn, B., Wolff, S., Sa, M., Yamasoe, M., Williams, J., Andreae, M.O., Kesselmeier, J., 2018. Monoterpene chemical speciation in a tropical rainforest: variation with season, height, and time of day at the Amazon Tall Tower Observatory (ATTO). Atmos. Chem. Phys. 18, 3403-3418. https://doi.org/10.5194/acp-18-3403-2018. 